This is the final peer-reviewed accepted manuscript of:

Ileana Ramazzina, Annachiara Berardinelli, Federica Rizzi, Silvia Tappi, Luigi Ragni, Giampiero Sacchetti, Pietro Rocculi, Effect of cold plasma treatment on physico-chemical parameters and antioxidant activity of minimally processed kiwifruit which has been published in final form in Postharvest Biology and Technology Volume 107, September 2015, Pages 55-65 The final published version is available online at: https://doi.org/10.1016/j.postharvbio.2015.04.008

(C) 2015 Elsevier. This manuscript version is made available under the Creative Commons Attribution-NonCommercialNoDerivs (CC BY-NC-ND) 4.0 International License (http://creativecommons.org/licenses/by-nc-nd/4.0/)

\title{
Effect of cold plasma treatment on physico-chemical parameters and antioxidant activity of minimally processed kiwifruit
}

\author{
Ileana Ramazzina ${ }^{\mathrm{a}}$, Annachiara Berardinelli ${ }^{\mathrm{b}}$, Federica Rizzi ${ }^{\mathrm{a}}$, Silvia Tappi ${ }^{\mathrm{c}, *}$, \\ Luigi Ragni $^{\text {b,c }}$, Giampiero Sacchetti ${ }^{\mathrm{d}}$, Pietro Rocculi ${ }^{\mathrm{b}, \mathrm{c}}$ \\ a Department of Biomedicine, Biotechnology and Translational Research, University of Parma, Via Volturno 39, 43125 Parma (PR), Italy \\ ${ }^{\mathrm{b}}$ Inter-Departmental Centre for Agri-Food Industrial Research, Alma Mater Studiorum, University of Bologna, Piazza Goidanich 60, 47521 Cesena (FC), Italy \\ ${ }^{\mathrm{c}}$ Department of Agricultural and Food Sciences, Alma Mater Studiorum, University of Bologna, Piazza Goidanich 60, 47521 Cesena (FC), Italy \\ d Faculty of Bioscience and Technology for Food, Agriculture and Environment, University of Teramo, Via C.R. Lerici, 67023 Mosciano Sant'Angelo, Teramo (TE), \\ Italy
}

\section{A B S T R A C T}

The efficacy of atmospheric plasma treatment on microbial decontamination of different kinds of food products is already known. Recently, new applications of thisinnovative technology have been proposed, in order to test the improvement of quality maintenance of minimally processed fruit and vegetables. Nevertheless, the knowledge on the modifications of functional and nutritional properties of minimally processed fruitistill scarce.

The objective of this study was to evaluate the effect of atmospheric double barrier discharge (DBD) plasma treatment on the quality maintenance of fresh-cut kiwifruit.Treatments of 10 and 20 min per side were performed and their consequences were evaluated during four daysoftorageicontrolled conditions by monitoring parameters related to visual quality, texture, chlorophyll, carotenoids and polyphenols. The in vitro antioxidant activity was evaluated through a multimodal approach, combining different assays for the analysis of antiradical activity and reducing activity of antioxidants. According to the obtained results, plasma treatments positively influenced thequality maintenance of the product, by improving colour retention and reducing the darkened area formation during storage, not inducing any textural change compared with the control. Plasma treatments caused an immediate slight loss of pigments, butbetter retention during storage. No significant changes in antioxidants content and antioxidant activity were observed among treated samples and control ones.

Keywords:

Cold plasma

Fresh-cut kiwifruit

Quality

Antioxidant activity

Antioxidants

\section{Introduction}

Among the known pre-treatments for extending storage life of minimally processed kiwifruit, some of the most used (in order of increasing intensity degree) include: dipping in calcium salt solutions, osmotic-dehydration, edible coating, tissue vacuum impregnation with glucose and hot water dipping (Muntada et al., 1998; Agar et al., 1999; Dalla Rosa et al., 2011; Tylewicz et al., 2011; Benítez et al., 2013). In terms of technological and economical aspects, these techniques present some disadvantages related to the necessity of dipping the product in aqueous solution (e.g. plant and consumables costs, disposal of exhausted solutions, labelling of chemical agents, further drying). In addition, these processing techniques are principally aimed at maintaining colour and texture

\footnotetext{
* Corresponding author. Tel.: +39 547 338120; fax: +39 547382348

E-mail address: silvia.tappi2@unibo.it (S. Tappi).
}

(Agar et al., 1999) and slowing down deteriorative phenomena induced by tissue wounding response, but not at sanitising the product.

Cold plasma is an ionised gas characterised by active particles such as electrons, ions, free radicals and atoms that is produced by applying energy to a gas or a gas mixture. Operative and configuration conditions of the atmospheric plasma generators and the assessment of the efficacy of the ionised gas on microbial inactivation were extensively reviewed (Moreau et al., 2008). The oxidative species produced during the discharge (reactive oxygen and nitrogen species) can cause peroxidation of lipids and oxidation of proteins and DNA (Montie et al., 2000).

Since the decontamination can be carried out in atmospheric conditions, the treatment was tested in terms of the efficacy of surface decontamination on different kinds of foods such as fruits (Berardinelli et al., 2012; Baier et al., 2014), vegetables (Keener et al., 2012; Baier et al., 2014), almonds (Deng et al., 2005), nuts (Basaran et al., 2008), grains and legumes (Selcuk et al., 2008), shell 
eggs (Ragni et al., 2010), hatching eggs (Pasquali et al., 2010) and meat (Noriega et al., 2011).

Recently, new applications of cold plasma have been proposed in the food processing sector. The oxidative power of plasma was tested in order to preserve the qualitative characteristics of fresh-cut fruit and vegetables. These applications were mainly addressed to the reduction of the activity of oxidative enzymes such as polyphenol oxidase in fresh-cut apples (Tappi et al., 2014; Bußler et al., 2013), peroxidase in tomatoes (Pankaj et al., 2013) and polyphenol oxidase and peroxidase in a model food system (Surowsky et al., 2013).

All the cited works evidenced a significant effect on the activity of degradative enzymes, in some cases with a consequent improvement of the product visual quality, as documented for fresh-cut Pink Lady apples (Tappi et al., 2014).

Other interesting works regard the effect of cold plasma on the total phenolic content of lamb's lettuce (Grzegorzewski et al., 2010, 2011) and on the physiological behaviour of green plant tissue (Baier et al., 2013, 2014). According to the aforementioned authors, plasma exposure leads to a detrimental effect on tissue photosynthetic efficiency, erosion phenomena of the leaves upper epidermis and a time and structure-dependent degradation of phenolic compounds, although the plant matrix seems to protect them from the oxidation caused by interaction with plasmainduced reactive species. In theory, the intense oxidative power of plasma treatment, due to the presence of $\mathrm{OH}^{\bullet}, \mathrm{NO}^{\bullet}$ and other reactive radical species (Ragni et al., 2010), could also promote the oxidation of the bioactive compounds contained in fruit tissue, such as vitamin $C$ and polyphenols, with a consequent decrease of the antioxidant properties of fresh fruit. Wang et al. (2012) found a slight decrease in the vitamin $\mathrm{C}$ content of different sliced vegetables subjected to microjet plasma treatment, probably due to oxidation, but within a range considered acceptable. The knowledge of the modifications on the functional and nutritional properties of minimally processed fruit is still scarce, and while there are some reports on the effect of plasma on the antioxidant content and activity of whole fruit (Berardinelli et al., 2012), the effect on fresh-cut fruit is largely unknown.
Among minimally processed fruit, kiwifruit is a very interesting product from a nutritional point of view because it contains high levels of vitamin C, vitamin E, flavonoids, minerals (Du et al., 2009) and significant amounts of pigments, including chlorophyll and carotenoids (Tavarini et al., 2008). Vitamin C is considered the major antioxidant compound in kiwifruit, contributing to about $40 \%$ of the total antioxidant activity (Tavarini et al., 2008), but also phenolic compounds have been reported to have a role in the antioxidant properties (Du et al., 2009). The consumption of kiwifruit has been recognised to have a preventative effect against different cancers due to its cytotoxic and antioxidant activities (Collins et al., 2001; Rush et al., 2002).

This study represents an early attempt to test the effect of double barrier discharge (DBD) cold plasma treatment on the quality of minimally processed kiwifruit and on its potential effect on health properties. In particular we monitored physical parameters related to visual quality (colour and darkened area), texture and standard chemical parameters. The chlorophyll, carotenoids, ascorbic acid and polyphenols content was also measured. The in vitro antioxidant activity was quantified by different in vitro assays: the 2,2'-azino-bis(3-ethylbenzothiazoline-6-sulphonic acid) (ABTS) radical scavenging assay, the 2,2-diphenyl-1-picrilhydrazyl $\left(\mathrm{DPPH}^{\bullet}\right)$ radical scavenging assay, and the ferric reducing antioxidant power (FRAP). The same parameters were tested during storage in controlled conditions.

\section{Materials and methods}

\subsection{Raw material, handling and storage}

Kiwifruits (Actinidia deliciosa cv. Hayward) were harvested at the beginning of November 2012 (Emilia Romagna region, Italy) and stored in a bin in a refrigerated room for one month (from $-1{ }^{\circ} \mathrm{C}$ to $1{ }^{\circ} \mathrm{C}$, R.H. 98\%). After this period, defect-free fruits of uniform size were selected and transported to the laboratory, where they were stored for a further $15 \mathrm{~d}$ at $4{ }^{\circ} \mathrm{C}$ and R.H. 98\% before being treated. At the time of sample preparation, the raw material had a soluble solid content of $13.5 \pm 0.77 \%$, titrable acidity

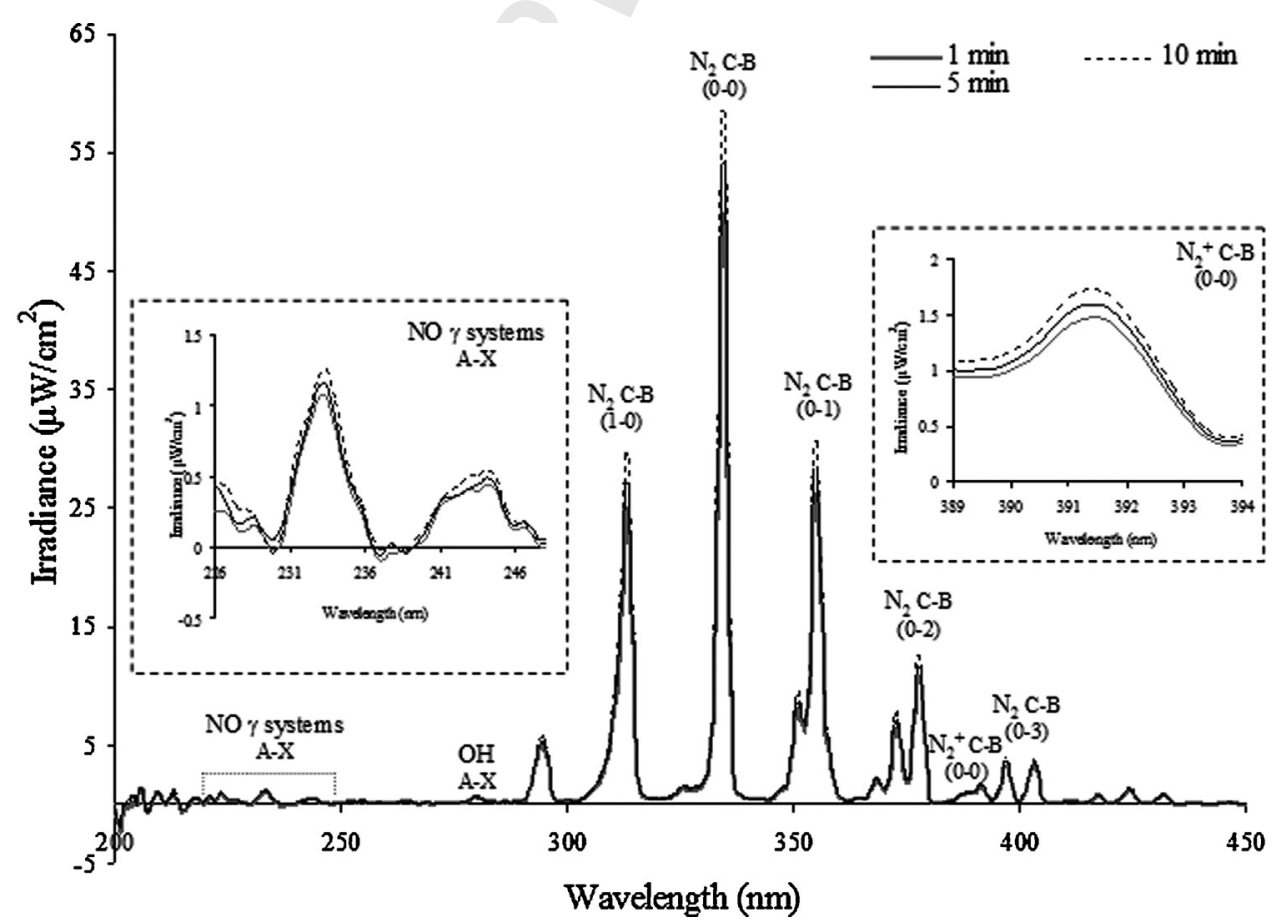

Fig. 1. Emission spectra of the discharge acquired during $10 \mathrm{~min}$ of treatment ( $15 \mathrm{kV}$ peak-to-peak, at about $22{ }^{\circ} \mathrm{C}$ and $60 \%$ of R.H.). 
of $1.47 \pm 0.07 \mathrm{~g}$ of citric acid kg-1 and a dry matter content of $149 \mathrm{~g} \pm 5.8 \mathrm{~kg}^{-1}$ on a fresh weight basis.

Analytical grade chemicals were purchased from SigmaAldrich (Steinheim, Germany). Hydrochloric acid and methanol were purchased from Romil (Feltham, UK).

\subsection{DBD gas plasma generator}

DBD cold plasma treatments were run at atmospheric conditions inside a cabinet described in previous studies (Ragni et al., 2010; Berardinelli et al., 2012). The ionised gas was produced using atmospheric gas (according to a DBD configuration) between three couples of parallel plate electrodes, made of brass (one electrode of each couple was covered by a $5 \mathrm{~mm}$ thick glass sheet as dielectric material). The electrodes were powered by a DC power supply whose voltage can be varied from 2 to $19 \mathrm{~V}$. As described in the cited studies, a potential difference of $15 \mathrm{kV}$ (peak-to-peak) was measured at the electrodes with an input voltage of $19 \mathrm{~V}$ (the level chosen for the treatment). The emission in the $200-450 \mathrm{~nm}$ wavelength range (at approximately $22^{\circ} \mathrm{C}$ and $60 \%$ of R.H.) was chemically characterised by an optic fibre probe (Avantes, FC-UV400-2) placed at $20 \mathrm{~mm}$ from the discharge and connected to a spectrometer (Avantes, AvaSpec-2048). Preliminary assessments showed that the presence of the fruit does not affect the emission during the duration of the treatments considered in this study.

The emission spectra acquired after 1,5 and 10 min of treatment are shown in Fig. 1. Probably due to a thermal stabilisation of the system (electrical components, electrodes, etc.), the measured irradiance increases by increasing the min of treatment. After about $10 \mathrm{~min}$, a stabilization of the irradiance values can be observed.

In terms of emission peaks, those related to the neutral nitrogen molecules $\mathrm{N}_{2}(290-440 \mathrm{~nm})$ and to the positive ion $\mathrm{N}_{2}{ }^{+}(391.4 \mathrm{~nm})$ were dominant, as can be commonly detected for atmospheric air discharge. The emission peaks of $\mathrm{OH}(305-309 \mathrm{~nm})$ and NO (226-248 nm) radicals were also observed.

\subsection{Sample treatment and storage}

Kiwifruit slices were placed under the electrodes (at a distance of $70 \mathrm{~mm}$ ) and the discharge was directed on the surface of the fruit by three fans mounted over the electrodes (fan speed: $1.5 \mathrm{~m} / \mathrm{s}$ at the base of the electrodes) as shown in Fig. 2.

After preliminary tests aimed at avoiding evident surface damage, two treatment times were chosen: $20 \mathrm{~min}(10+10 \mathrm{~min}$ for each side) and $40 \mathrm{~min}(20+20 \mathrm{~min}$ for each side). Atmospheric conditions (approximately $22^{\circ} \mathrm{C}$ and $60 \%$ R.H.) were defined according to previous experiences which showed that $\mathrm{OH}$ radicals increase by increasing the air humidity level (Ragni et al., 2010).

Each treatment $(10+10$ and $20+20)$ was repeated in triplicate and for each replication 30 slices from 10 different kiwifruit were used. To minimise differences due to natural variability, kiwifruit slices were randomly divided into two sub-samples of 15 treated and 15 control samples. Control samples were stored at the same temperature and R.H. conditions for the duration of the treatment.

Kiwifruit slices were stored for four days in controlled and constant conditions; in particular, temperature and relative humidity were respectively $10^{\circ} \mathrm{C}$ and $95 \%$ in order to simulate an accelerated storage. The storage temperature was chosen in order to simulate an accelerated storage that requires the use of a temperature higher than the optimal one, but, at the same time, in order to avoid the change of the typology of degradative reactions, a temperature close to the real storage condition in the supermarket was chosen.

Furthermore, to avoid interaction with packaging variables such as passive modified atmosphere, samples were placed on trays and stored unpacked. Colour, visual quality by image analysis and texture were assessed for each treatment immediately after the plasma exposition and after one and four days of storage.

To analyse chlorophyll and carotenoids content, samples were freeze-dried after treatment and after four days of storage. They were subsequently ground under liquid nitrogen and stored at $-18^{\circ} \mathrm{C}$ for two weeks.

Antioxidants content and antioxidant activity were determined only on samples subjected to the longest treatment and their relative controls after freeze-drying.

\subsection{Qualitative assessment}

\subsubsection{Visual quality}

2.4.1.1. Colour. Surface colour was measured on the kiwifruit pericarp with a Chroma Meter CR-400 reflectance colorimeter (Minolta Italia, Milano, Italy) using the D65 illuminant and the $10^{\circ}$ standard observer. For each slice, an average value of three measurements performed in three different points was calculated. The $L^{*}, a^{*}$ and $b^{*}$ parameters of the CIELAB system were measured, $a^{*}$ and $b^{*}$ parameters were further used to calculate Hue angle (Eq. (1)) and chroma (Eq. (2)) values (C.I.E., 1987).

$\mathrm{h}^{\circ}=\left(\frac{\arctan \left[b^{*} / a^{*}\right]}{2 \pi}\right) \times 360$

Chroma $=\sqrt{\mathrm{a}^{* 2}+\mathrm{b}^{* 2}}$

2.4.1.2. Darkened area by computer vision system (CVS). A digital camera mod. D7000 (Nikon, Shinjuku, Japan) equipped with a $60 \mathrm{~mm}$ lens AF-S micro, Nikkor (Nikon, Shinjuku, Japan) was used to acquire digitalised images of kiwifruit slices (exposition time $0.5 \mathrm{~s}$; F-stop $\mathrm{f} / 16$ ) placed inside a black box under controlled lighting condition.

Images (RGB scale) were processed with Photoshop (Adobe Photoshop, 8.0) in order to separate the pericarp area from the core tissue. These two portions were separately analysed with an

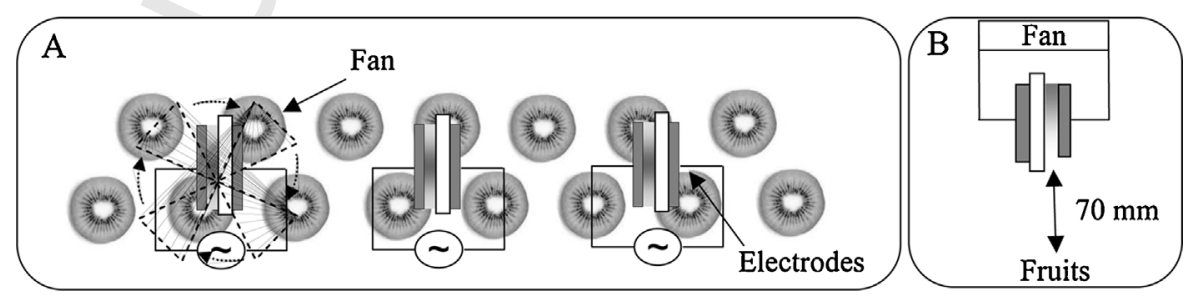

Fig. 2. Top view of the electrodes and of the kiwifruit slices placed under the discharge. 
advanced Image Analysis Software (Image Pro-Plus v. 6.2, Media Cybernetics, USA), according to a chromatic model set up by Rocculi et al. (2005). After conversion in grey scale (8 BPP), on the basis of the chromatic characteristics, two different pixel ranges were defined corresponding to "darkened" (0-177 BPP for pericarp and 0-215 BPP for the core) and "not darkened" (178-253 BPP 216-153 BPP for the core) areas. All pixels were then evaluated by the model in terms of percentage of darkened area on the total.

\subsubsection{Texture}

Penetration tests were run using a Texture Analyser TA-HDi500 (Stable Micro Systems, Surrey, UK) equipped with a $50 \mathrm{~N}$ load cell and a $6 \mathrm{~mm}$ diameter stainless steel cylinder by setting the test speed at $0.5 \mathrm{~mm} \mathrm{~s}^{-1}$ and the maximum deformation at $90 \%$.

For each slice, penetration tests were carried out in two different points of the pericarp. The acquired curves (Force, N, versus time, s) were analysed and the following mechanical parameters were extracted: firmness, the first peak force $(\mathrm{N})$ value representing the limit of the flesh elasticity $(\mathrm{F})$, work $(\mathrm{mJ})$ required to rupture the flesh from $0 \mathrm{~s}$ to $\mathrm{F}(\mathrm{AF})$, and gradient $\left(\mathrm{N} \mathrm{mm}^{-1}\right)$ between $0 \mathrm{~s}$ and $\mathrm{F}(\mathrm{G})$.

\subsubsection{Chemical parameters}

Soluble solids content (SSC) was determined at $20^{\circ} \mathrm{C}$ by measuring the refractive index with a digital refractometer mod. PR1 (Atago Co., Ltd., Tokyo, Japan) calibrated with distilled water.

Dry matter content was determined gravimetrically by difference in weight before and after drying at $70^{\circ} \mathrm{C}$, until a constant weight was achieved (AOAC International, 2002).

Titratable acidity (TA) was determined by titration with $\mathrm{NaOH}$ $0.1 \mathrm{~N}$ until pH 8.1 was reached (AOAC International, 2000), and expressed as mg of citric acid $\mathrm{kg}^{-1}$ on a fresh weight basis.

For each sample, SSC and TA were determined in triplicate on the juice obtained by crushing 10 kiwifruit slices with a food processor, after filtering through Whatman \#1 filter paper. SSC, dry matter and TA were determined immediately after treatment and after $24 \mathrm{~h}$ of storage in controlled conditions $\left(10^{\circ} \mathrm{C}, 90 \%\right.$ R.H.).

Electrolyte leakage (EL) was measured as described by Rolny et al. (2011) with small modifications. Briefly, one slice of kiwifruit (approx $10 \mathrm{~g}$ ) was floated on $100 \mathrm{~mL}$ of deionised water. The electrolyte content in the solution was measured immediately $\left(C_{0}\right)$ and after $3 \mathrm{~h}\left(C_{3}\right)$ of incubation under continuous shaking at room temperature using a conductometer (Crison Instrument, Barcelona, Spain). The flasks were then put in an oven at $100^{\circ} \mathrm{C}$ for $1 \mathrm{~h}$. After cooling to room temperature, total conductivity (TC) was then measured again. Results were expressed as percentage of electrolyte leakage according to Eq. (3):

$\% \mathrm{EL}=100 \times \frac{\left(C_{3}-C_{0}\right)}{\mathrm{TV}}$

Electrolyte leakage was measured in order to assess a possible cell membrane damage, as an increased value of this parameter indicates disruption of the plasma membrane.

\subsubsection{Chlorophyll and carotenoids content}

$0.5 \mathrm{~g}$ of freeze-dried sample were extracted for $2 \mathrm{~min}$ with $5 \mathrm{~mL}$ of $80 \%$ acetone and centrifuged $\left(3273 \times \mathrm{g}\right.$ for $10 \mathrm{~min}$ at $\left.10^{\circ} \mathrm{C}\right)$. The supernatant was directly assayed spectrophotometrically at three different wavelengths (662, 645 and $470 \mathrm{~nm}$ ). Quantifications were obtained according to Lichtenthaler and Wellburn (1983) using the Eqs. (4)-(6):

$C_{\mathrm{a}}=11.75 \times A_{662}-2.350 \times A_{645}$
$C_{\mathrm{b}}=18.61 \times A_{645}-3.960 \times A_{662}$

$C_{\mathrm{s}}=\frac{1000 \times A_{470}-2.270 C_{\mathrm{a}}-81.4 C_{\mathrm{b}}}{227}$

where $C_{\mathrm{a}}, C_{\mathrm{b}}$ and $C_{\mathrm{s}}$ are respectively chlorophyll a and $\mathrm{b}$ and carotenoids concentrations $\left(\mathrm{mg} \mathrm{L}^{-1}\right)$, and $A$ is the absorbance values at the different wavelengths. Results were expressed as $\mathrm{g} \mathrm{kg}^{-1}$ of dry weight.

\subsubsection{Antioxidants and antioxidant activity}

2.4.5.1. Sample preparation and solid phase extraction for antioxidants determination. Hydrophilic fraction extraction: $0.5 \mathrm{~g}$ of freezedried sample were added to $10 \mathrm{~mL}$ of $0.1 \mathrm{~N}$ sulphuric acid in a $50 \mathrm{~mL}$ polypropylene tube, wrapped in an aluminium sheet. The mixture was vortexed for $2 \mathrm{~min}$, then was centrifuged for $10 \mathrm{~min}$ at $1500 \times \mathrm{g}$ in an Allegra ${ }^{\mathrm{TM}} \mathrm{X}-22$ R centrifuge (Beckman Coulter, Inc., Brea, CA) set at $4{ }^{\circ} \mathrm{C}$. The supernatant was filtered through a Whatman 541 filter paper (GE Healthcare, Buckinghamshire, UK). The solid residue was stored at $4{ }^{\circ} \mathrm{C}$ and then used for the extraction of amphiphilic fraction. $4 \mathrm{~mL}$ of the sample was loaded onto a Strata C18-U cartridge connected to a vacuum manifolds system (Phenomenex Inc., Torrance, CA, USA) and previously conditioned with $10 \mathrm{~mL}$ of methanol $100 \%$ followed by $25 \mathrm{~mL}$ of water. After the complete absorption of the sample, the hydrophilic compounds were eluted with $2 \times 4 \mathrm{~mL}$ of $0.1 \mathrm{~N}$ sulphuric acid, collected in a $15 \mathrm{~mL}$ polypropylene tube (final volume $12 \mathrm{~mL}$ ) and used for antioxidants and antioxidant activity determinations.

Amphiphilic fraction extraction: $1 \mathrm{~mL}$ of methanol $100 \%$ was added to the solid residue obtained after hydrophilic compounds extraction and it was dried under a gentle nitrogen stream. Sample was then added to $10 \mathrm{~mL}$ of methanol $60 \%$ and vigorously shaken for $10 \mathrm{~min}$ at room temperature. The mixture was centrifuged for $10 \mathrm{~min}$ at $1500 \times \mathrm{g}$ in an Allegra ${ }^{\mathrm{TM}} \mathrm{X}-22 \mathrm{R}$ centrifuge (Beckman Coulter, Inc., Brea, CA) set at $4{ }^{\circ} \mathrm{C} .4 \mathrm{~mL}$ of the supernatant were loaded onto the same C-18 cartridge previously used for the separation of the hydrophilic fraction. After the complete absorption of the sample, the amphiphilic compounds were eluted with $2 \times 4 \mathrm{~mL}$ of methanol $60 \%$, collected in a $15 \mathrm{~mL}$ polypropylene tube (final volume $12 \mathrm{~mL}$ ) and used for antioxidants and antioxidant activity determinations.

2.4.5.2. Ascorbic acid determination. Ascorbic acid was determined on the hydrophilic extract by HPLC analysis carried out according to Odriozola-Serrano et al. (2007). The HPLC system LC-1500 (Jasco, Carpi, MO, Italy) was equipped with a diode array UV/vis detector. A reverse-phase $\mathrm{C} 18$ Kinetex (Phenomenex Inc., Torrance, CA, USA) stainless steel column $(4.6 \mathrm{~mm} \times 150 \mathrm{~mm})$ was used as stationary phase. Samples were introduced in the column through an autosampler (Jasco AS-2055 Plus). The mobile phase was a $0.01 \%$ solution of sulphuric acid adjusted to $\mathrm{pH} 2.6$. Flow rate was fixed at $1.0 \mathrm{~mL} / \mathrm{min}$ at room temperature. Data were processed by the software ChromNAV (ver. 1.16.02) from Jasco. Ascorbic acid content was quantified at $245 \mathrm{~nm}$ through a standard calibration curve that was linear in the range $0-284 \mu \mathrm{M}$ ascorbic acid.

2.4.5.3. Total phenolic content (TPC) determination. The content of total polyphenols was quantified by the Folin-Ciocalteu phenol reagent method, according to Singleton and Rossi (1965), modified to fit a 96-wells plate. The TPC depends on the specific phenolic profile, in particular the type of phenolics present and their relative amounts or proportions (Naczk and Shahidi, 2004). The analysis was carried out after solid phase extraction on C-18 cartridges, 
which has been reported as a suitable technique of separation for phenolic compounds (Antolovich et al., 2000; Nackzk and Shaidi, 2004).

The fresh working solution was prepared daily by diluting Folin -Ciocalteu phenol reagent to a final concentration of $0.6 \mathrm{~N}$ in water.

$250 \mu \mathrm{L}$ of Folin-Ciocalteu phenol reagent were aliquoted in a 96-well microplate and the reaction was started by adding $60 \mu \mathrm{L}$ of hydrophilic or amphiphilic extracts. Six different dilutions for each extract were analysed. After 6 min in the darkness the reaction was neutralised by the addition of $22 \mu \mathrm{L}$ of sodium carbonate $0.3 \mathrm{~g} \mathrm{~mL}^{-1}$. After an incubation of $30 \mathrm{~min}$ at room temperature in the darkness, the absorbance was measured at $765 \mathrm{~nm}$ using the EnSpire $^{\mathrm{TM}}$ Multimode Plate Reader (PerkinElmer, Waltham, MA). $60 \mu \mathrm{L}$ of $0.1 \mathrm{~N}$ sulphuric acid or methanol $60 \%$ were used for the blank sample, for hydrophilic or amphiphilic extracts respectively.

Gallic acid was used as standard for the calculation of total phenolic content of hydrophilic and amphiphilic extracts. Gallic acid was dissolved in water for hydrophilic extract and in methanol $60 \%$ for the amphiphilic extract. $60 \mu \mathrm{L}$ of water or methanol $60 \%$ were used for the blank sample, for hydrophilic or amphiphilic extracts respectively. The standard curve was linear in the range $0-39 \mu \mathrm{M}$ gallic acid.

2.4.5.4. Radical scavenging capacity by $A B T S^{\bullet+}$. The ABTS free radical scavenging activity was determined according to the method described by Re et al. (1999) and modified to fit a 96-wells plate. Briefly, ABTS was dissolved in deionised water to a final concentration of $7 \mathrm{mM}$ and $\mathrm{ABTS}^{\bullet+}$ was produced by reacting ABTS solution with potassium persulphate $2.45 \mathrm{mM}$ and allowing the mixture to stand in the dark at room temperature for $12-16 \mathrm{~h}$. $\mathrm{ABTS}^{\bullet+}$ was then aliquoted into small vials for storage at $-80^{\circ} \mathrm{C}$ until used. For the study, the ABTS $^{\bullet+}$ solution was diluted in deionised water to an absorbance of $1.829 \pm 0.028$ at $734 \mathrm{~nm}$. Fresh diluted $\mathrm{ABTS}^{\bullet+}$ solution was prepared daily.

$250 \mu \mathrm{L}$ of $\mathrm{ABTS}^{\bullet+}$ were aliquoted in a 96-wells microplate and the reaction was started by adding $30 \mu \mathrm{L}$ or $60 \mu \mathrm{L}$ of hydrophilic or amphiphilic extracts, respectively. Six different dilutions for each extract were analysed. After $5 \mathrm{~min}$ of incubation at room temperature in the darkness, $\mathrm{ABTS}^{\bullet}$ blanching was measured at $734 \mathrm{~nm}$ using the EnSpire ${ }^{\mathrm{TM}}$ Multimode Plate Reader (PerkinElmer,
Waltham, MA). $30 \mu \mathrm{L}$ or $60 \mu \mathrm{L}$ of $0.1 \mathrm{~N}$ sulphuric acid or methanol $60 \%$ were used for the blank solution, for hydrophilic or amphiphilic extracts respectively.

Trolox was used as standard for the calculation of the radical scavenging activity (RSA) of hydrophilic or amphiphilic extracts. Trolox was dissolved in PBS buffer ( $\mathrm{pH}$ 7.3) for hydrophilic extract and in methanol $60 \%$ for the amphiphilic extract. $30 \mu \mathrm{L}$ of PBS or $60 \mu \mathrm{L}$ of methanol $60 \%$ were used for the blank sample for hydrophilic or amphiphilic extracts, respectively. The standard curve was linear in the range $0-58 \mu \mathrm{M}$ Trolox.

2.4.5.5. Radical scavenging capacity by $D P P H^{\circ}$. The DPPH free radical scavenging activity was determined according to the method described by Brand-Williams et al. (1995) modified to fit a 96-wells plate. The $\mathrm{DPPH}^{\bullet}$ stock solution $0.913 \mathrm{mM}$ was prepared in methanol $100 \%$ and was stored at $-20^{\circ} \mathrm{C}$ until used. The working solution was obtained diluting $\mathrm{DPPH}^{\bullet}$ stock solution in methanol $60 \%$ to a final concentration of $0.290 \mathrm{mM}$. Fresh diluted solution was prepared daily. $250 \mu \mathrm{L}$ of $\mathrm{DPPH}^{\bullet}$ were aliquoted in a 96 -wells microplate and the reaction was started by adding $60 \mu \mathrm{L}$ of amphiphilic extract. Six different dilutions of amphiphilic extract were analysed. $\mathrm{DPPH}^{\bullet}$ reduction was measured at $515 \mathrm{~nm}$ using the EnSpire $^{\mathrm{TM}}$ Multimode Plate Reader (PerkinElmer, Waltham, MA) at $25^{\circ} \mathrm{C}$, after $10 \mathrm{~min}$ of reaction at room temperature in the darkness. $60 \mu \mathrm{L}$ of methanol $60 \%$ were used for the blank sample. Trolox was used as standard for the calculation of the RSA of amphiphilic extract. Trolox was dissolved in methanol $60 \%$ and the standard curve was linear in the range $0-58 \mu \mathrm{M}$ Trolox. $60 \mu \mathrm{L}$ of methanol $60 \%$ were used for the blank solution.

2.4.5.6. FRAP determination. The FRAP assay was carried out according to the method described by Benzie and Strain (1996), modified to fit a 96-wells plate. The FRAP reagent ( $1.67 \mathrm{mM}$ ferric

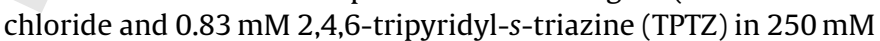
acetate buffer, $\mathrm{pH}$ 3.6) was prepared daily.

$250 \mu \mathrm{L}$ of FRAP reagent was aliquoted in a 96-wells microplate and the reaction was started by adding $60 \mu \mathrm{L}$ of amphiphilic extract. Six different dilutions of amphiphilic extract were analysed. After $6 \mathrm{~min}$ of reaction at room temperature in the darkness, the absorbance was measured at $593 \mathrm{~nm}$ using the

Table 1

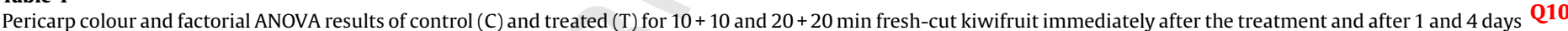
of storage.

\begin{tabular}{|c|c|c|c|c|c|c|c|c|}
\hline \multirow[t]{2}{*}{ Sample } & \multirow[t]{2}{*}{ Treatment time (min) } & \multirow[t]{2}{*}{ Storage time $(\mathrm{d})$} & \multicolumn{2}{|c|}{ Lightness } & \multicolumn{2}{|c|}{ Chroma } & \multicolumn{2}{|c|}{ Hue angle $\left(^{\circ}\right)$} \\
\hline & & & Mean & s.d & Mean & s.d. & Mean & s.d. \\
\hline$C$ & $10+10$ & 0 & $49.3^{\mathrm{a}}$ & 5.5 & $30.1^{\mathrm{a}}$ & 6.8 & $120.4^{\mathrm{a}}$ & 2.3 \\
\hline $\mathrm{T}$ & $10+10$ & 0 & $47.6^{\mathrm{ab}}$ & 6.2 & $27.1^{\mathrm{ab}}$ & 8.1 & $120.2^{\mathrm{a}}$ & 2.4 \\
\hline C & $20+20$ & 0 & $47.5^{\mathrm{ab}}$ & 5.7 & $29.0^{\mathrm{ab}}$ & 7.0 & $119.9^{\mathrm{a}}$ & 2.6 \\
\hline $\mathrm{T}$ & $20+20$ & 0 & $46.4^{\mathrm{abc}}$ & 4.8 & $26.2^{\mathrm{b}}$ & 6.3 & $120.7^{\mathrm{a}}$ & 3.5 \\
\hline C & $10+10$ & 1 & $44.7^{\text {abce }}$ & 8.4 & $20.1^{\mathrm{cd}}$ & 4.5 & $111.5^{\mathrm{b}}$ & 7.1 \\
\hline $\mathrm{T}$ & $10+10$ & 1 & $46.2^{\mathrm{abc}}$ & 7.4 & $18.6^{\mathrm{cd}}$ & 3.8 & $111.6^{\mathrm{b}}$ & 3.7 \\
\hline C & $20+20$ & 1 & $43.0^{\text {cde }}$ & 6.9 & $19.0^{\text {cd }}$ & 4.6 & $112.5^{\mathrm{b}}$ & 3.3 \\
\hline $\mathrm{T}$ & $20+20$ & 1 & $48.1^{\mathrm{a}}$ & 9.3 & $19.7^{\mathrm{c}}$ & 5.1 & $111.4^{\mathrm{b}}$ & 2.9 \\
\hline C & $10+10$ & 4 & $39.9^{\mathrm{df}}$ & 6.4 & $18.4^{\mathrm{ab}}$ & 4.4 & $112.5^{\mathrm{b}}$ & 5.5 \\
\hline $\mathrm{T}$ & $10+10$ & 4 & $43.2^{\text {bcde }}$ & 6.4 & $21.1^{c}$ & 4.6 & $112.1^{\mathrm{b}}$ & 6.3 \\
\hline C & $20+20$ & 4 & $37.3^{f}$ & 5.4 & $16.7^{\mathrm{d}}$ & 3.5 & $112.4^{\mathrm{b}}$ & 4.3 \\
\hline $\mathrm{T}$ & $20+20$ & 4 & $41.1^{\mathrm{def}}$ & 6.5 & $17.7^{\mathrm{ab}}$ & 4.7 & $111.1^{\mathrm{b}}$ & 3.3 \\
\hline $\mathrm{F}$ & Sample & & 10.1 & $* *$ & 1.11 & n.s. & 0.01 & n.s. \\
\hline $\mathrm{F}$ & S.t. & & 57.1 & $* * *$ & 171 & $* * *$ & 237 & $* * *$ \\
\hline $\mathrm{F}$ & Sample $\times$ S.t. & & 8.00 & $* * *$ & 8.32 & $* * *$ & 0.75 & n.s. \\
\hline $\mathrm{F}$ & T.t. & & 4.57 & ${ }^{* *}$ & 6.83 & ${ }^{* * *}$ & 0.99 & n.s \\
\hline $\mathrm{F}$ & T.t. $\times$ S.t. & & 1.48 & n.s. & 2.44 & n.s. & 0.55 & n.s. \\
\hline
\end{tabular}

C: control; T: treated; F: F value; S.t.: storage time; T.t.: treatment time, s.d.: standard deviation; n.s.: not significant.

Data marked with the same letter within each column are not significantly different at a $p<0.05$ level.

${ }^{*} p<0.05$.

${ }^{* * *} p<0.01$ 
EnSpire $^{\mathrm{TM}}$ Multimode Plate Reader (PerkinElmer, Hamburg, Germany). $60 \mu \mathrm{L}$ of methanol $60 \%$ were used for the blank sample.

$\mathrm{Fe}_{2} \mathrm{SO}_{4}$ dissolved in water was used as standard for the calculation of the reduction capacity of amphiphilic extract. The standard curve was linear in the range $0-174 \mu \mathrm{M} \mathrm{Fe}_{2} \mathrm{SO}_{4} .60 \mu \mathrm{L}$ of water were used for the blank sample.

Results of TPC, $\mathrm{ABTS}^{\bullet+}$, DPPH ${ }^{\bullet}$ and FRAP are expressed in mol of standard $\mathrm{kg}^{-1}$ on a dry weight basis of freeze-dried sample and were calculated by the ratio of the correlation coefficient of the dose-response curve of sample, and the correlation coefficient of the dose-response curve of the standard.

\subsection{Statistical analysis}

All the analyses were carried out at least in triplicate on 3 independent samples and results were reported as mean and standard deviation.

Factorial analysis of variance (ANOVA) was carried out to test the significance of the effects of treatment (sample), storage time (S.t.), and their interaction (sample $\times$ S.t.); the effect of treatment time (T.t.) and its interaction with storage time (T.t. $\times$ S.t.) was further studied within treated samples.

Significant differences $(p<0.05)$ between mean values were tested by the Tukey's HSD test. In the case of significance of the Levene test, non parametric Mann-Whitney test was used.

Correlations among the results of different antioxidant activity assays were calculated by Pearson's correlation analysis. Statistical analyses were carried out using the software STATISTICA for Windows 7 (StatsoftTM, Tulsa, OK).

\section{Results and discussion}

\subsection{Visual quality}

\subsubsection{Colour}

Mean values and standard deviations of the colorimetric parameters obtained from the measurements conducted on the pericarp of the kiwifruit slices are shown in Table 1.

Samples lightness significantly decreased during storage but, although no significant differences among control and treated samples were observed immediately after the treatment, plasma showed a positive effect on colour lightness maintenance during storage, finally resulting in a less darkened product.

According to Agar et al. (1999), surface darkening of kiwifruit slices can be attributed to translucent water soaking from the tissue, since low polyphenol oxidase activity and high ascorbate content limit enzymatic browning.

Plasma treatments did not affect colour Hue angle and saturation (chroma), whilst the latter was affected by treatment time. Storage time after treatment significantly decreased both parameters.

\subsubsection{Darkened area by CVS}

In Table 2, mean values and standard deviations of the darkened area (\%) calculated for the pericarp and the core areas of the kiwifruit slices are reported.

Storage time significantly increased the extent of darkened areas, and, even though no significant differences were observed immediately after the treatment, plasma treated samples showed a more limited darkening during storage compared to control samples due to the interactive effect between sample and storage time.

Furthermore, a significant interactive effect between treatment time and storage time on the extension of darkened areas of the pericarp was observed, with sample treated for long time presenting a faster darkening than those treated for the shortest
Table 2

Pericarp and core darkened area and factorial ANOVA results of control (C) and treated $(\mathrm{T})$ for $10+10$ and $20+20 \mathrm{~min}$ fresh-cut kiwifruit immediately after the treatment and after 1 and 4 days of storage.

\begin{tabular}{|c|c|c|c|c|c|c|}
\hline \multirow[t]{3}{*}{ Sample } & \multirow[t]{3}{*}{ Treatment time (min) } & \multirow[t]{3}{*}{ Storage time (d) } & \multicolumn{4}{|c|}{ Darkened area } \\
\hline & & & \multicolumn{2}{|c|}{ Pericarp (\%) } & \multicolumn{2}{|c|}{ Core (\%) } \\
\hline & & & Mean & s.d & Mean & s.d. \\
\hline C & $10+10$ & 0 & $5.73^{c}$ & 4.60 & $8.70^{c}$ & 9.09 \\
\hline $\mathrm{T}$ & $10+10$ & 0 & $13.2^{\mathrm{c}}$ & 18.5 & $13.5^{\mathrm{c}}$ & 9.36 \\
\hline C & $20+20$ & 0 & $13.4^{\mathrm{c}}$ & 11.6 & $15.4^{\mathrm{c}}$ & 16.3 \\
\hline $\mathrm{T}$ & $20+20$ & 0 & $19.7^{c}$ & 13.0 & $21.4^{\mathrm{c}}$ & 25.8 \\
\hline C & $10+10$ & 1 & $16.9^{c}$ & 7.97 & $28.0^{c}$ & 17.0 \\
\hline $\mathrm{T}$ & $10+10$ & 1 & $8.00^{c}$ & 6.34 & $23.2^{c}$ & 15.3 \\
\hline C & $20+20$ & 1 & $55.8^{\mathrm{b}}$ & 19.4 & $61.5^{\mathrm{b}}$ & 19.3 \\
\hline $\mathrm{T}$ & $20+20$ & 1 & $21.7^{\mathrm{c}}$ & 8.84 & $25.0^{c}$ & 15.5 \\
\hline C & $10+10$ & 4 & $95.8^{\mathrm{a}}$ & 4.93 & $70.7^{\mathrm{ab}}$ & 27.8 \\
\hline $\mathrm{T}$ & $10+10$ & 4 & $82.3^{\mathrm{a}}$ & 24.0 & $63.3^{\mathrm{ab}}$ & 22.5 \\
\hline C & $20+20$ & 4 & $94.0^{\mathrm{a}}$ & 10.1 & $87.5^{\mathrm{a}}$ & 23.8 \\
\hline $\mathrm{T}$ & $20+20$ & 4 & $79.2^{\mathrm{a}}$ & 23.7 & $60.8^{\mathrm{ab}}$ & 27.6 \\
\hline $\mathrm{F}$ & Sample & & 18.61 & ${ }^{* * * *}$ & 12.39 & $* * *$ \\
\hline $\mathrm{F}$ & S.t. & & 435.7 & ${ }^{* * *}$ & 108.7 & ${ }^{* * *}$ \\
\hline $\mathrm{F}$ & Sample $\times$ S.t. & & 14.41 & ${ }^{* * * *}$ & 7.40 & ${ }^{* * * *}$ \\
\hline $\mathrm{F}$ & T.t. & & 21.60 & $* * *$ & 12.23 & $* * *$ \\
\hline $\mathrm{F}$ & T.t. $\times$ S.t. & & 14.91 & ${ }^{* * *}$ & 1.35 & n.s. \\
\hline
\end{tabular}

C: control; T: treated; F: F value; S.t.: storage time; T.t.: treatment time, s.d.: standard deviation; n.s.: not significant.

Data marked with the same letter within each column are not significantly different at a $p<0.05$ level.

${ }^{*} p<0.05$.

$p<0.01$.

time, but resulting in similar final values of darkened area at the end of the storage. Visual examples of control samples and treated samples $(20+20 \mathrm{~min})$ after $4 \mathrm{~d}$ of storage are given in Fig. 3 .

\subsection{Texture}

Results of the penetration test are reported in Table 3. DBD cold plasma treatment did not affect the texture of kiwifruit slices in terms of hardness, work necessary to rupture the flesh and gradient. Storage time determined a dramatic decrease of all the texture parameters after 4 days of storage which were neither influenced by the treatment nor by the treatment time.

According to Varoquaux et al. (1990) and Rocculi et al. (2005), texture breakdown in kiwifruit slices is due to physiological events that include enzymatic mediated degradation of hemicellulose,

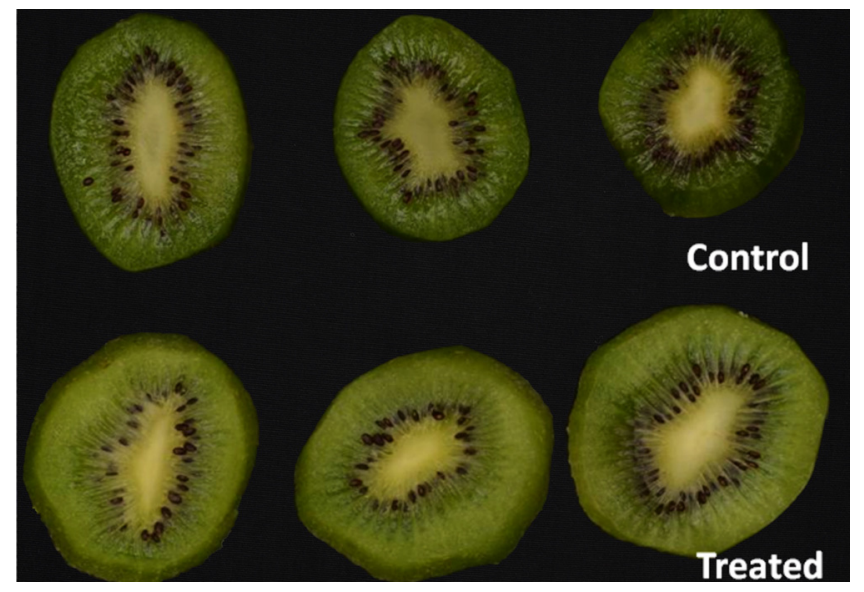

Fig. 3. Example of digitalised images of kiwifruit slices subjected to $20+20 \mathrm{~min}$ DBD gas plasma treatment and control ones acquired after 4 days of storage in controlled conditions. 
Table 3

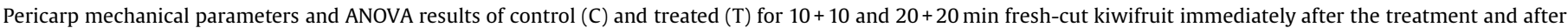
1 and 4 days of storage.

\begin{tabular}{|c|c|c|c|c|c|c|c|c|}
\hline \multirow[t]{2}{*}{ Sample } & \multirow[t]{2}{*}{ Treatment time (min) } & \multirow[t]{2}{*}{ Storage time $(\mathrm{d})$} & \multicolumn{2}{|c|}{ Hardness $(\mathrm{N})$} & \multicolumn{2}{|c|}{ Energy to rupture (mJ) } & \multicolumn{2}{|c|}{ Gradient $\left(\mathrm{N} \mathrm{mm}^{-1}\right)$} \\
\hline & & & Mean & s.d & Mean & s.d & Mean & s.d \\
\hline C & $10+10$ & 0 & $6.3^{\mathrm{ab}}$ & 2.3 & $4.60^{\mathrm{a}}$ & 1.86 & $9.38^{\mathrm{ab}}$ & 2.37 \\
\hline $\mathrm{T}$ & $10+10$ & 0 & $6.8^{\mathrm{a}}$ & 1.8 & $4.81^{\mathrm{a}}$ & 1.63 & $9.62^{\mathrm{ab}}$ & 3.26 \\
\hline C & $20+20$ & 0 & $6.0^{\mathrm{ab}}$ & 2.1 & $4.57^{\mathrm{a}}$ & 2.09 & $9.16^{\mathrm{ab}}$ & 3.65 \\
\hline $\mathrm{T}$ & $20+20$ & 0 & $5.3^{\mathrm{b}}$ & 2.3 & $4.20^{\mathrm{a}}$ & 2.29 & $8.12^{\mathrm{b}}$ & 3.24 \\
\hline C & $10+10$ & 1 & $5.2^{\mathrm{b}}$ & 1.8 & $4.81^{\mathrm{a}}$ & 1.77 & $8.85^{\mathrm{ab}}$ & 2.84 \\
\hline $\mathrm{T}$ & $10+10$ & 1 & $6.3^{\mathrm{a}}$ & 1.9 & $4.47^{\mathrm{a}}$ & 1.53 & $10.93^{\mathrm{a}}$ & 3.05 \\
\hline C & $20+20$ & 1 & $5.0^{\mathrm{b}}$ & 1.8 & $4.27^{\mathrm{a}}$ & 1.42 & $9.37^{\mathrm{ab}}$ & 3.54 \\
\hline $\mathrm{T}$ & $20+20$ & 1 & $5.4^{\mathrm{ab}}$ & 1.9 & $4.69^{\mathrm{a}}$ & 1.82 & $9.15^{\mathrm{ab}}$ & 2.94 \\
\hline C & $10+10$ & 4 & $2.0^{\mathrm{c}}$ & 0.5 & $1.84^{\mathrm{a}}$ & 1.17 & $3.67^{c}$ & 2.34 \\
\hline $\mathrm{T}$ & $10+10$ & 4 & $2.0^{\mathrm{c}}$ & 0.6 & $1.68^{\mathrm{a}}$ & 0.79 & $3.35^{\mathrm{c}}$ & 1.58 \\
\hline C & $20+20$ & 4 & $1.8^{\mathrm{c}}$ & 0.8 & $1.54^{\mathrm{a}}$ & 0.89 & $3.08^{\mathrm{c}}$ & 1.78 \\
\hline $\mathrm{T}$ & $20+20$ & 4 & $1.7^{\mathrm{c}}$ & 0.7 & $1.47^{\mathrm{a}}$ & 0.89 & $2.94^{c}$ & 1.78 \\
\hline $\mathrm{F}$ & Sample & & 1.01 & n.s. & 0.63 & n.s. & 0.26 & n.s. \\
\hline $\mathrm{F}$ & S.t. & & 202 & ${ }^{* * *}$ & 350 & $* * *$ & 1364 & $* * *$ \\
\hline $\mathrm{F}$ & Sample $\times$ S.t. & & 2.11 & n.s. & 1.79 & n.s. & 2.38 & n.s. \\
\hline $\mathrm{F}$ & T.t. & & 8.09 & 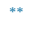 & 5.13 & & 4.07 & \\
\hline $\mathrm{F}$ & T.t. $\times$ S.t. & & 0.93 & n.s. & 0.37 & n.s. & 0.17 & n.s. \\
\hline
\end{tabular}

C: control; T: treated; F: F value; S.t.: Storage time; T.t.: treatment time, s.d.: standard deviation; n.s.: not significant.

Data marked with the same letter within each column are not significantly different at a $p<0.05$ level.

${ }^{*} p<0.05$.

*** $p<0.01$.

$p<0.001$.

solubilization of polyuronide and release of galactose from pectic polymers, cell wall swelling and a decrease in water and osmotic potential. Although in previous studies it has been reported that plasma treatment can promote enzyme inactivation (Pankaj et al., 2013; Surowsky et al., 2013; Tappi et al., 2014), in this research, the activity of enzymes responsible for structure breakdown, generally activated by operations such as peeling and cutting, do not seem to be influenced by the applied treatments. To our knowledge, no researches have yet been carried out on the effect of plasma reactive species nor on this type of enzymes nor in this matrix (kiwifruit), hence, at the moment, to hypothesise a mechanism to explain the different results would be too speculative.

\subsection{Chemical parameters}

Mean values and standard deviations of soluble solid content (SSC), titrable acidity (TA), electrolyte leakage (EL) and dry matter (DM) are reported in Table 4.

SSC increased with storage time probably due to starch conversion into sugars but was not affected by the treatment. Nevertheless, a significant interactive effect was observed between treatment time and storage time as samples treated for longer time showed a more pronounced increased of SSC.

TA was significantly affected by storage time, treatment time and their interactions, although considering treated and control

Table 4

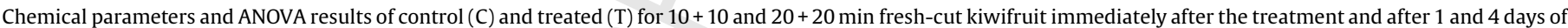
storage.

\begin{tabular}{|c|c|c|c|c|c|c|c|c|c|c|}
\hline \multirow[t]{2}{*}{ Sample } & \multirow[t]{2}{*}{ Treatment time (min) } & \multirow[t]{2}{*}{ Storage time $(\mathrm{d})$} & \multicolumn{2}{|c|}{ SSC (\%) } & \multicolumn{2}{|c|}{$\mathrm{TA}$ ( $\mathrm{mg}$ citric acid $\mathrm{kg}^{-1}$ ) } & \multicolumn{2}{|l|}{$\mathrm{EL}(\%)$} & \multicolumn{2}{|l|}{ DM (\%) } \\
\hline & & & Mean & s.d & Mean & s.d & Mean & s.d & Mean & s.d \\
\hline C & $10+10$ & 0 & $15.3^{\mathrm{b}}$ & 0.6 & $13.1^{\mathrm{a}}$ & 1.0 & $67.3^{a}$ & 2.6 & $10.9^{d}$ & 0.6 \\
\hline $\mathrm{T}$ & $10+10$ & 0 & $15.4^{\mathrm{b}}$ & 1.1 & $13.6^{\mathrm{a}}$ & 0.7 & $61.6^{\mathrm{a}}$ & 6.7 & $11.7^{\mathrm{cd}}$ & 0.3 \\
\hline C & $20+20$ & 0 & $14.1^{\mathrm{bc}}$ & 0.4 & $11.2^{\mathrm{a}}$ & 1.0 & $59.9^{\mathrm{a}}$ & 0.3 & $12.2^{\mathrm{d}}$ & 0.7 \\
\hline $\mathrm{T}$ & $20+20$ & 0 & $14.9^{\mathrm{bc}}$ & 0.5 & $11.7^{\mathrm{a}}$ & 0.5 & $61.9^{\mathrm{a}}$ & 0.5 & $13.0^{c}$ & 0.3 \\
\hline C & $10+10$ & 1 & $16.2^{\mathrm{d}}$ & 0.3 & $14.2^{\mathrm{b}}$ & 0.7 & $55.6^{\mathrm{a}}$ & 4.6 & $11.9^{\mathrm{cd}}$ & 0.7 \\
\hline $\mathrm{T}$ & $10+10$ & 1 & $16.9^{\mathrm{d}}$ & 0.3 & $16.7^{\mathrm{b}}$ & 3.1 & $63.1^{\mathrm{a}}$ & 7.7 & $13.2^{\mathrm{C}}$ & 0.2 \\
\hline C & $20+20$ & 1 & $18.2^{\mathrm{d}}$ & 1.5 & $15.4^{\mathrm{b}}$ & 0.9 & $60.9^{\mathrm{a}}$ & 3.0 & $13.1^{\mathrm{c}}$ & 0.2 \\
\hline $\mathrm{T}$ & $20+20$ & 1 & $17.2^{\mathrm{d}}$ & 0.7 & $16.7^{\mathrm{b}}$ & 0.5 & $55.2^{\mathrm{a}}$ & 3.0 & $14.3^{\mathrm{e}}$ & 0.2 \\
\hline C & $10+10$ & 4 & $19.0^{\mathrm{a}}$ & 0.8 & $17.3^{c}$ & 0.4 & $73.7^{\mathrm{a}}$ & 5.7 & $22.3^{\mathrm{e}}$ & 1.0 \\
\hline $\mathrm{T}$ & $10+10$ & 4 & $17.7^{\mathrm{d}}$ & 0.2 & $14.0^{\mathrm{a}}$ & 0.7 & $66.7^{\mathrm{a}}$ & 4.8 & $20.1^{\mathrm{b}}$ & 0.1 \\
\hline C & $20+20$ & 4 & $17.6^{\mathrm{d}}$ & 0.2 & $13.7^{\mathrm{a}}$ & 1.0 & $66.4^{\mathrm{a}}$ & 2.2 & $21.8^{\mathrm{a}}$ & 1.0 \\
\hline $\mathrm{T}$ & $20+20$ & 4 & $19.4^{\mathrm{a}}$ & 0.3 & $13.6^{\mathrm{a}}$ & 0.7 & $66.7^{\mathrm{a}}$ & 1.8 & $22.4^{\mathrm{e}}$ & 1.2 \\
\hline $\mathrm{F}$ & Sample & & 0.64 & n.s. & 0.65 & n.s. & 0.26 & n.s. & 3.42 & n.s. \\
\hline $\mathrm{F}$ & S.t. & & 79.13 & & 47.94 & $* * *$ & 7.25 & $* *$ & 793.56 & $* * *$ \\
\hline $\mathrm{F}$ & Sample $\times$ S.t. & & 0.52 & n.s. & 13.21 & ${ }^{* * *}$ & 1.42 & n.s. & 8.01 & $* *$ \\
\hline $\mathrm{F}$ & T.t. & & 0.43 & n.s. & 14.76 & $* * *$ & 0.52 & n.s. & 26.64 & *** \\
\hline $\mathrm{F}$ & T.t. $\times$ S.t. & & 6.80 & & 8.71 & $* *$ & 0.25 & n.s. & 0.33 & n.s. \\
\hline
\end{tabular}

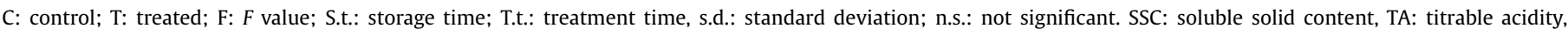
EL: electrolyte leakage, DM: dry matter.

Data marked with the same letter within each column are not significantly different at a $p<0.05$ level.

${ }^{*} p<0.05$.

${ }^{* * *} p<0.01$ 
samples at each storage day, the only significant differences observed by Tukey's HSD mean comparison test was after $4 \mathrm{~d}$ of storage for the $10+10$ sample.

EL is a measurement of membrane integrity and it is often used to assess the effect of stress or senescence on plant tissue (Rolny et al., 2011). As it can be observe in Table 4, this parameter was affected only by storage time, although no significant differences were found according to the Tukey's HSD mean comparison test. Hence, it can be assumed that the treatment did not affect cell membrane integrity.

Dry matter content underwent an increase of about $7 \%$ compared to the control immediately after the treatment for both samples, probably due to the effect of the fan, similarly to the result found by Wang et al. (2012). During storage, a progressive increase was observed in all samples but, as the interaction between sample and storage time shows, plasma treatment seems to have induced a faster dehydration of the tissue exposed to the air. After the longer treatment, differences in dry matter compared to controls were more pronounced as it can be observed in Table 4 .

Generally, the obtained results showed that the response of kiwifruit tissue to plasma treatment in terms of physico-chemical parameters was limited and mainly represented by an increased of dry matter content.

\subsection{Chlorophyll and carotenoids analysis}

Mean values and standard deviations of the concentration of the chlorophyll $\mathrm{a}$ and $\mathrm{b}$ and of the carotenoids are reported in Table 5.

A significant decrease in chlorophyll a (about 15\%) was observed soon after treatment, even though no significant differences among control and treated samples were observed after $4 \mathrm{~d}$ of storage. Storage time significantly decreased the chlorophyll and carotenoids content, but plasma treated samples showed a more limited pigments loss than control samples.

The chlorophyll degradation upon plasma treatment could be associated to the Type II breakdown mechanism (Brown et al., 1991), which is mediated by the presence of oxygen radicals produced during reactions related to tissue metabolism or, as in this case, by plasma. Their presence is favoured by membrane breakdown as it normally occurs in minimally processed fruit and vegetable products. Hence, it can be hypothesised that the free radicals produced during the treatments caused the first pigments oxidation. At the same time, plasma is known to produce a partial protein denaturation (Pankaj et al., 2013; Surowsky et al., 2013; Tappi et al., 2014), which may have caused a slowdown in chlorophyll catabolism operated by enzymes such as chlorophyllase and magnesium dechelatase (Type I breakdown) during storage.

\subsection{Ascorbic acid and total phenolic content}

Ascorbic acid and TPC of treated and control kiwifruit samples were evaluated and the results are summarised in Table 6.

The minimally processed kiwifruit samples showed an average ascorbic acid content of $33 \mathrm{~mol} \mathrm{~kg}^{-1}$ on a dry weight basis, higher than values reported by other authors (Agar et al., 1999; Gil et al., 2006; Tavarini et al., 2008) ranging between 20 and $25 \mathrm{~mol} \mathrm{~kg}^{-1}$ on a dry weight basis. However, Tavarini et al. (2008) showed that the ascorbic acid content of kiwifruit could vary more than two-fold due to harvest time and post-harvest storage.

The DBD plasma treatment did not affect the ascorbic acid content (Table 6) immediately after the treatment, but a significant reduction of ascorbic acid of about $7 \%$ after $4 \mathrm{~d}$ of storage was highlighted by ANOVA, even though the Tukey's HSD mean comparison test did not evidence significant difference among the samples.

Agar et al. (1999) found a $20 \%$ reduction of ascorbic acid in kiwifruit slices after $6 \mathrm{~d}$ of storage at $10^{\circ} \mathrm{C}$ due to oxidation, while Gil et al. (2006) found a 10\% reduction of ascorbic acid after $4 \mathrm{~d}$ of storage at $5^{\circ} \mathrm{C}$ and a $13 \%$ reduction after $6 \mathrm{~d}$.

The TPC of the hydrophilic extracts resulted higher than that of the amphiphilic extracts, even though $\mathrm{C}-18$ cartridges retain most of the phenolic compounds. This happens because the ascorbic acid in the hydrophilic extract, whose recovery was $95 \%$ as determined by the standard addition method, could react with the Folin-Ciocalteu reagent (Antolovich et al., 2000; Vinson et al., 2001). This fact is often overwhelmed when discussing total polyphenols data. The analysis of TPC without separation of the hydrophilic fraction (i.e. by SPE) could determine a dramatic overestimation of kiwifruit TPC. For example Tavarini et al. (2008) detected about $16 \mathrm{~mol} \mathrm{~kg}^{-1}$ on a dry weight basis of total phenolics in kiwifruit using the colorimetric assay with the Folin-Ciocalteu reagent without SPE separation, whilst other authors (Gil et al., 2006; Dawes and Keene, 1999) detected about $1.6 \mathrm{~mol} \mathrm{~kg}^{-1}$ of total phenolics by HPLC analysis. In this study, a total phenolic content of

Table 5

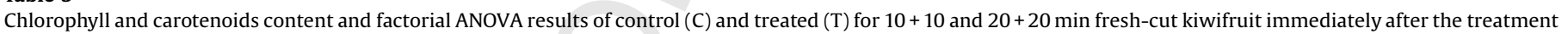
and after 4 days of storage. Data are expressed on dry weight basis.

\begin{tabular}{|c|c|c|c|c|c|c|c|c|}
\hline \multirow[t]{2}{*}{ Sample } & \multirow[t]{2}{*}{ Treatment time (min) } & \multirow[t]{2}{*}{ Storage time $(\mathrm{d})$} & \multicolumn{2}{|c|}{ Chlorophyll a $\left(\mathrm{g} \mathrm{kg}^{-1}\right)$} & \multicolumn{2}{|c|}{ Chlorophyll b $\left(\mathrm{g} \mathrm{kg}^{-1}\right)$} & \multicolumn{2}{|c|}{ Total carotenoids $\left(\mathrm{g} \mathrm{kg}^{-1}\right)$} \\
\hline & & & Mean & s.d & Mean & s.d. & Mean & s.d. \\
\hline C & $10+10$ & 0 & $100.5^{\mathrm{a}}$ & 8.04 & $43.97^{\mathrm{ab}}$ & 4.41 & $42.02^{\mathrm{ab}}$ & 3.31 \\
\hline $\mathrm{T}$ & $10+10$ & 0 & $87.15^{b}$ & 2.08 & $38.83^{a b c}$ & 3.38 & $40.69^{\mathrm{abc}}$ & 0.50 \\
\hline $\mathrm{C}$ & $20+20$ & 0 & $100.0^{\mathrm{a}}$ & 3.45 & $44.19^{\mathrm{a}}$ & 4.00 & $43.35^{\mathrm{a}}$ & 3.49 \\
\hline $\mathrm{T}$ & $20+20$ & 0 & $86.44^{\mathrm{b}}$ & 3.12 & $41.73^{\mathrm{abc}}$ & 2.93 & $40.21^{\mathrm{abc}}$ & 2.31 \\
\hline $\mathrm{C}$ & $10+10$ & 4 & $88.16^{\mathrm{b}}$ & 3.29 & $37.32^{c}$ & 3.29 & $37.52^{\mathrm{cd}}$ & 0.21 \\
\hline $\mathrm{T}$ & $10+10$ & 4 & $90.53^{b}$ & 4.19 & $42.65^{a b c}$ & 2.75 & $38.34^{\mathrm{bcd}}$ & 3.44 \\
\hline $\mathrm{C}$ & $20+20$ & 4 & $88.16^{\mathrm{b}}$ & 4.29 & $37.32^{\mathrm{C}}$ & 3.29 & $37.52^{\mathrm{cd}}$ & 0.21 \\
\hline $\mathrm{T}$ & $20+20$ & 4 & $89.59^{\mathrm{b}}$ & 4.65 & $37.78^{b c}$ & 4.24 & $35.20^{d}$ & 4.55 \\
\hline $\mathrm{F}$ & Sample & & 26.79 & ${ }^{* * *}$ & 0.21 & n.s. & 4.84 & \\
\hline $\mathrm{F}$ & S.t. & & 15.61 & ${ }^{* * *}$ & 11.34 & ${ }^{* *}$ & 42.44 & ${ }^{* * *}$ \\
\hline $\mathrm{F}$ & Sample $\times$ S.t. & & 47.28 & ${ }^{* * *}$ & 10.89 & ** & 1.19 & n.s. \\
\hline $\mathrm{F}$ & T.t. & & 0.24 & n.s. & 0.18 & n.s. & 0.19 & n.s. \\
\hline $\mathrm{F}$ & T.t. $\times$ S.t. & & 0.00 & n.s. & 3.89 & n.s. & 2.16 & n.s. \\
\hline
\end{tabular}

C: control; T: treated; F: F value; S.t.: storage time; T.t.: treatment time, s.d.: standard deviation; n.s.: not significant.

Data marked with the same letter within each column are not significantly different at a $p<0.05$ level.

$p<0.05$.

${ }^{* *} p<0.01$.

$p<0.001$. 
Table 6

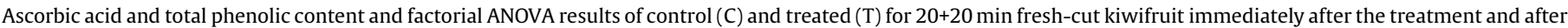
$4 \mathrm{~d}$ of storage. Data are expressed on dry weight basis.

\begin{tabular}{|c|c|c|c|c|c|c|c|}
\hline \multirow[t]{3}{*}{ Sample } & \multirow[t]{3}{*}{ Storage time $(\mathrm{d})$} & \multirow{2}{*}{\multicolumn{2}{|c|}{$\begin{array}{l}\text { Ascorbic acid content }\left(\mathrm{mol} \mathrm{kg}^{-1}\right) \\
\text { Hydrophilic extract }\end{array}$}} & \multicolumn{4}{|c|}{ Total phenolic content $\left(\mathrm{mol} \mathrm{kg}^{-1}\right)$} \\
\hline & & & & \multicolumn{2}{|c|}{ Hydrophilic extract } & \multicolumn{2}{|c|}{ Amphiphilic extract } \\
\hline & & Mean & s.d. & Mean & s.d. & Mean & s.d. \\
\hline $\mathrm{C}$ & 0 & $34.86^{\mathrm{a}}$ & 1.65 & $7.54^{\mathrm{a}}$ & 0.38 & $4.48^{\mathrm{a}}$ & 0.62 \\
\hline $\mathrm{T}$ & 0 & $36.69^{a}$ & 0.81 & $7.91^{\mathrm{a}}$ & 0.57 & $4.21^{\mathrm{ab}}$ & 0.62 \\
\hline $\mathrm{C}$ & 4 & $31.52^{\mathrm{a}}$ & 2.41 & $7.25^{\mathrm{a}}$ & 0.33 & $3.21^{\mathrm{bc}}$ & 0.10 \\
\hline $\mathrm{T}$ & 4 & $35.15^{a}$ & 1.83 & $7.56^{\mathrm{a}}$ & 0.36 & $2.88^{\mathrm{c}}$ & 0.35 \\
\hline $\mathrm{F}$ & Sample & 0.59 & n.s. & 1.51 & n.s. & 0.14 & n.s. \\
\hline $\mathrm{F}$ & S.t. & 5.67 & & 1.40 & n.s. & 23.2 & ${ }^{* * *}$ \\
\hline $\mathrm{F}$ & Sample $\times$ S.t. & 0.02 & n.s. & 0.01 & n.s. & 0.06 & n.s. \\
\hline
\end{tabular}

C: control; T: treated; F: F value; S.t.: storage time; T.t.: treatment time, s.d.: standard deviation; n.s.: not significant.

Data marked with the same letter within each column are not significantly different at a $p<0.05$ level.

${ }^{* * *} p<0.01$.

${ }^{*} p<0.05$.

$p<0.001$.

about $4 \mathrm{~mol} \mathrm{~kg}^{-1}$ was measured in the amphiphilic fraction after SPE separation; this amount can be considered comparable with previously reported results, since the TPC of kiwifruit can show up to three-fold variations due to harvest time and post-harvest storage (Tavarini et al., 2008).

The DBD plasma treatment did not affect the response to the Folin-Ciocalteu reagent in both the hydrophilic and the amphiphilic extract (Table 6). A significant reduction of TPC in the amphiphilic extract of about $30 \%$ after $4 \mathrm{~d}$ of storage was highlighted by ANOVA analysis.

In fresh-cut fruit tissues, phenols could undergo chemical or enzymatic oxidation mediated by polyphenol oxidase (PPO) or peroxidase (POD); however, as a consequence to wounding, new phenolic compounds can also be synthesised through an increase of the activity of the enzyme phenylalanine ammonia lyase (PAL) as a defence mechanism (Heredia and Cisneros-Zevallos, 2009). In this study, the TPC of the kiwifruit amphiphilic extract, accounting for polyphenols, decreased after $4 \mathrm{~d}$ of storage whilst Gil et al. (2006) did not find any TPC variation during storage of fresh-cut kiwifruits at $5{ }^{\circ} \mathrm{C}$ for $9 \mathrm{~d}$ these differences could be due to the different storage conditions adopted.

\subsection{Antioxidant activity (AOA) determination}

In the present study, the antioxidant activity of kiwifruit samples was investigated with a variety of methods aimed to measure their RSA and reducing power (Table 7).
The ABTS $^{\bullet+}$ assay was conducted on both the hydrophilic and amphiphilic extracts; the former showed a radical scavenging activity much higher (about 5-fold) than the latter probably because kiwifruit is very rich in ascorbic acid and less in polyphenols. Since the amount of ascorbic acid in kiwifruits was measured and the relative radical scavenging activity of this molecule is known (Re et al., 1999) it is possible to assume that all the antioxidant activity of the hydrophilic extract is due to ascorbic acid.

Even though the TPC in kiwifruit is about $4 \mathrm{~mol} \mathrm{~kg}^{-1}$ on a dry weight basis (taking into account only the amphiphilic fraction) and ascorbic acid is about $33 \mathrm{~mol} \mathrm{~kg}^{-1}$, the former accounts for about the $40 \%$ of total TEAC (Trolox equivalent antioxidant capacity) and the latter for the remaining 60\%. This data are in complete accordance with those found by Tavarini et al., (2008) using different analytical assays.

DBD plasma treatment did not affect the TEAC of both the hydrophilic and the amphiphilic extract; similar results were also found using the other antioxidant activity assays (DPPH and FRAP), which were carried out on the amphiphilic extracts. The DBD plasma treatment adopted in this study did not affected the antioxidant activity and antioxidants content of kiwifruit. Even though the DBD plasma-induced reactive species could have caused the oxidation of single phenolic compounds responsible for the antioxidant activity of minimally processed kiwifruit, this effect was counteracted by tissue response mechanisms.

Table 7

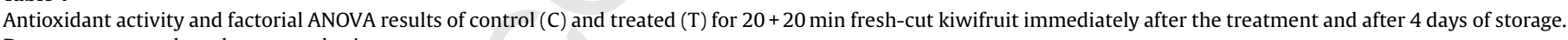
Data are expressed on dry matter basis.

\begin{tabular}{|c|c|c|c|c|c|c|c|c|c|}
\hline \multirow[t]{3}{*}{ Sample } & \multirow[t]{3}{*}{ Storage time $(\mathrm{d})$} & \multicolumn{4}{|c|}{$\mathrm{RSA}_{\mathrm{ABTS}}\left(\mathrm{mol} \mathrm{TE} \mathrm{kg}^{-1}\right)$} & \multirow{2}{*}{\multicolumn{2}{|c|}{$\frac{\mathrm{RSA}_{\mathrm{DPPH}}\left(\mathrm{mol} \mathrm{TE} \mathrm{kg}{ }^{-1}\right)}{\text { Amphiphilic extract }}$}} & \multirow{2}{*}{\multicolumn{2}{|c|}{$\left.\frac{\text { FRAP }(\mathrm{mol} \mathrm{TE} \mathrm{kg}}{-1}\right)$}} \\
\hline & & \multicolumn{2}{|c|}{ Hydrophilic extract } & \multicolumn{2}{|c|}{ Amphiphilic extract } & & & & \\
\hline & & Mean & s.d. & Mean & s.d. & Mean & s.d. & Mean & s.d. \\
\hline $\mathrm{C}$ & 0 & $22.46^{\mathrm{a}}$ & 0.19 & $4.89^{\mathrm{a}}$ & 0.19 & $8.89^{a}$ & 0.42 & $9.49^{\mathrm{a}}$ & 0.42 \\
\hline $\mathrm{T}$ & 0 & $23.35^{\mathrm{a}}$ & 0.55 & $4.75^{\mathrm{ab}}$ & 0.44 & $8.66^{\mathrm{a}}$ & 0.66 & $8.56^{\mathrm{ab}}$ & 0.66 \\
\hline C & 4 & $20.77^{\mathrm{b}}$ & 0.45 & $4.22^{\mathrm{b}}$ & 0.45 & $8.74^{\mathrm{a}}$ & 0.64 & $8.13^{\mathrm{b}}$ & 0.64 \\
\hline $\mathrm{T}$ & 4 & $21.37^{b}$ & 0.79 & $4.23^{\mathrm{ab}}$ & 0.57 & $9.28^{\mathrm{a}}$ & 0.59 & $8.18^{\mathrm{b}}$ & 0.59 \\
\hline $\mathrm{F}$ & Sample & 6.97 & $*$ & 0.09 & n.s. & 0.02 & n.s. & 1.64 & n.s. \\
\hline $\mathrm{F}$ & S.t. & 56.8 & $* * *$ & 7.16 & & 0.54 & n.s. & 6.30 & \\
\hline $\mathrm{F}$ & Sample $\times$ S.t. & 0.72 & n.s. & 0.15 & n.s. & 0.02 & n.s. & 2.01 & n.s. \\
\hline
\end{tabular}

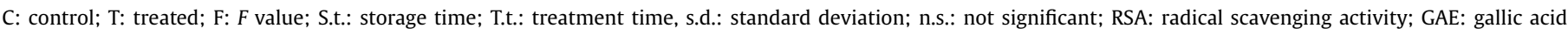
equivalents; TE: Trolox equivalents.

Data marked with the same letter within each column are not significantly different at a $p<0.05$ level.

$p<0.01$.

${ }^{*} p<0.05$

$p<0.001$ 
Table 8

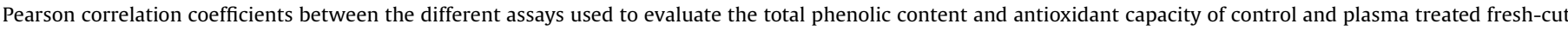
kiwifruit.

\begin{tabular}{|c|c|c|c|c|c|c|}
\hline & \multicolumn{2}{|c|}{ Total phenolic content, TPC $\left(\mathrm{mol} \mathrm{kg}^{-1}\right)$} & \multicolumn{2}{|l|}{$\mathrm{RSA}_{\mathrm{ABTS}}\left(\mathrm{mol} \mathrm{kg}^{-1}\right.$} & \multirow{2}{*}{$\begin{array}{l}\mathrm{RSA}_{\mathrm{DPPH}}\left(\mathrm{mol} \mathrm{kg}^{-1}\right) \\
\text { Amphiphilic } \\
\text { extract }\end{array}$} & \multirow{2}{*}{$\begin{array}{l}\text { FRAP }\left(\mathrm{mol} \mathrm{kg}^{-1}\right) \\
\text { Amphiphilic extract }\end{array}$} \\
\hline & Hydrophilic extract & Amphiphilic extract & Hydrophilic extract & Amphiphilic extract & & \\
\hline TPC hydrophylic extract & 1.000 & 0.412 & 0.365 & 0.543 & 0.291 & 0.279 \\
\hline TPC amphiphilic extract & 0.412 & 1.000 & 0.682 & $0.782^{* *}$ & -0.082 & $0.804^{* *}$ \\
\hline RSA $_{\mathrm{ABTS}}$ hydrophilic extract & 0.365 & 0.682 & 1.000 & 0.511 & 0.156 & 0.370 \\
\hline $\mathrm{RSA}_{\mathrm{ABTS}}$ amphiphilic extract & 0.543 & $0.782^{* *}$ & 0.511 & 1.000 & 0.034 & $0.843^{* *}$ \\
\hline $\mathrm{RSA}_{\mathrm{DPPH}}$ amphiphilic extract & 0.291 & -0.082 & 0.156 & 0.034 & 1.000 & -0.215 \\
\hline FRAP amphiphilic extract & 0.279 & $0.804^{* *}$ & 0.370 & $0.843^{* *}$ & -0.215 & 1.000 \\
\hline
\end{tabular}

RSA: radical scavenging activity; GAE: gallic acid equivalents; TE: Trolox equivalents. ${ }^{*} p<0.05 ;{ }^{* *+*} p<0.001$.

$p<0.01$.

The antioxidant activity of both the hydrophilic and amphiphilic extracts decreased with storage time (Table 7), except for the $\mathrm{DPPH}^{\bullet}$ assay which did not evidence any difference in AOA after storage, thus showing a lower sensibility than the other assays. Antioxidant constituents of vegetable tissues are susceptible to degradation when exposed to oxygen or light, or upon interaction with enzymes, such as ascorbate oxidase, polyphenol oxidase, cytochrome oxidase and peroxidase as a consequence of wounding (Gil et al., 2006). Several studies have been performed regarding the effect of wounding response on antioxidant activity (Kang and Saltveit, 2002; Reyes and Cisneros-Zevallos, 2003; Reyes et al., 2007; Heredia and Cisneros-Zevallos, 2009). Results generally indicate that changes in the antioxidant activity as a consequence of wounding depend on the type of tissue, the initial content of ascorbic acid and phenolic compounds, and the specific phenolic profile.

The Pearson correlation analysis was performed to correlate results obtained with different methods (Table 8). A significant correlation between the $\mathrm{ABTS}^{\bullet+}$ and the FRAP applied to the amphiphilic fraction was found despite the different reaction mechanisms implied in the two assays. Noteworthy, both these assays were strongly correlated with the TPC when they were carried out on the amphiphilic fraction of kiwifruit extract, which contains only polyphenols. The TPC is based on the capacity of phenolic compounds to react with the Folin-Ciocalteu reagent under basic conditions and thus has been extensively used as a method for the estimation of total phenolics; nonetheless, taking into account that polyphenols show different reactivity with the Folin-Ciocalteu reagent (Nazck and Shahidi, 2004) and that the mechanism is based on a oxidation/reduction reaction, TPC can be also considered an antioxidant method (Prior et al., 2005). The results of the $\mathrm{DPPH}^{\bullet}$ assay a less sensible method than the others in evidencing changes in the AOA of the amphiphilic fraction, carried out in methanolic medium, were neither correlated with those of other antioxidant methods nor with the TPC.

\section{Conclusions}

According to the obtained results, the DBD cold plasma treatments promoted an immediate loss of pigment and visual quality on minimally processed kiwifruit but positively influenced the quality maintenance of the product, by improving colour retention and reducing the darkened area formation over storage time in controlled conditions. In addition, although DBD cold plasma treatment had an effect in increasing dry matter content over storage, it did not induced any textural changes compared with the control.

In general, no significant changes in antioxidants (ascorbic acid and polyphenols) content and antioxidant activity were observed among treated samples and control ones.
In this direction the purposed DBD plasma treatment is a very promising tool to preserve the quality of minimally processed kiwifruit.

Further studies will be necessary to confirm the sanitising effect of DBD plasma already showed for different commodities on minimally processed kiwifruit and the eventual sensorial properties modification induced by the treatment.

\section{Acknowledgments}

The authors acknowledge the financial support of the Italian Ministry for Education, Universities and Research (FIRB, Project RBFR100CEJ: Innovative approach for the study of fresh-cut fruit: qualitative, metabolic and functional aspects).

\section{References}

Agar, I.T., Massantini, R., Hess-Pierce, B., Kader, A.A., 1999. Postharvest $\mathrm{CO}_{2}$ and ethylene production and quality maintenance of fresh-cut kiwifruit slices. J. Food Sci. 64, 433-440.

Antolovich, M., Prenzler, P., Robards, K., Ryan, D., 2000. Sample preparation in the determination of phenolic compounds in fruits. Analyst 125, 989-1009.

AOAC International, 2000. Official Methods of Analysis (OMA) of AOAC International, USA. Method number: 942.15. Available at: http://www.eoma. aoac.org/.

AOAC International, 2002. Official Methods of Analysis (OMA) of AOAC International, seventeenth ed., USA. Method number: 920.15. Available at: http://www.eoma.aoac.org/.

Baier, M., Foerster, J., Schabel, U., Knorr, D., Herppich, W.B., Schlüter, O., 2013. Direct non-thermal plasma treatment for the sanitation of fresh corn salad leaves: evaluation of physical and physiological effects and antimicrobial efficacy. Postharvest Biol. Technol. 84, 81-87.

Baier, M., Görgen, M., Ehlbeck, J., Knorr, D., Herppich, W.B., Schlüter, O., 2014. Nonthermal atmospheric pressure plasma: screening for gentle process conditions and antibacterial efficiency on perishable fresh produce. Innovative Food Sci. Emerg. Technol. 22, 147-257.

Basaran, P., Basaran-Akgul, N., Oksuz, L., 2008. Elimination of Aspergillus parasiticus from nut surface with low pressure cold plasma (LPCP) treatment. Food Microbiol. 25 (4), 626-632.

Benítez, S., Achaerandio, I., Sepulcre, F., Pujolà, M., 2013. Aloe vera based edible coatings improve the quality of minimally processed 'Hayward' kiwifruit. Postharvest Biol. Technol. 81, 29-36.

Benzie, I.F.F., Strain, J.J., 1996. The ferric reducing ability of plasma (FRAP) as a measure of antioxidant power: the FRAP assay. Anal. Biochem. 239, 70-76.

Berardinelli, A., Vannini, L., Ragni, L., Guerzoni, M.E., 2012. Impact of atmospheric plasma generated by a DBD device on quality-related attributes of Abate Fetel pear fruit. Plasma for Bio-Decontamination, Medicine and Food Security, NATO Science for Peace and Security Series A: Chemistry and Biology. Springer.

Brand-Williams, W., Cuvelier, M.E., Berset, C., 1995. Use of a free radical method to evaluate antioxidant activity. Lebensm. Wiss. Technol. 28, 25-30.

Brown, S.B., Houghton, J.D., Hendry, G.A.F., 1991. Chlorophyll breakdown. In: Scheer, H. (Ed.), Chlorophylls. Boca Raton, FL, pp. 465-489.

Bußler, S., Schnabel, U., Ehlbeck, J., Schlueter, O., 2013. Effects of indirect plasma treatment on enzyme activity and quality of fresh cut and freeze dried apple tissue. Proceedings of the EFFOST 2013 Annual Meeting number P1.064.

C.I.E, 1987. In: Wien, A. (Ed.), Colorimetry. second ed. Central Bureaux of the Commission Internationale de l'Eclaraige.

Collins, B.H., Horska, A., Hotten, P.M., Riddoch, C., Collins, A.R., 2001. Kiwifruit protects against oxidative DNA damage in human cells and in vitro. Nutr. Cancer Int. J. 39, 148-153. 
Dalla Rosa, M., Tylewicz, U., Panarese, V., Laghi, L., Pisi, A., Santagapita, P., Rocculi, P., 2011. Effect of osmotic dehydration on kiwifruit: results of a multianalytical approach to structural study. J. Process. Energy Agric. 15, 113-117.

Dawes, H.M., Keene, J.B., 1999. Phenolic composition of kiwifruit juice. J. Agric. Food Chem. 47, 2398-2403.

Deng, S., Ruan, R., Mok, C.K., Huang, G., Chen, P., 2005. Non-thermal plasma disinfection of Escherichia coli on almond. ASAE Meeting Presentation Paper Number: 056149

Du, G., Li, M., Ma, F., Liang, D., 2009. Antioxidant capacity and the relationship with polyphenol and Vitamin C in Actinidia fruits. Food Chemistry 113, 557-562.

Gil, M.I., Aguayo, E., Kader, A.A., 2006. Quality changes and nutrient retention in fresh cut versus whole fruits during storage. J. Agric. Food Chem. 54, 4284-4296.

Grzegorzewski, F., Ehlbeck, J., Schlüter, O., Kroh, L.W., Rohn, S., 2011. Treating lamb’s lettuce with a cold plasma-influence of atmospheric pressure $\mathrm{Ar}$ immanent species on the phenolic profile of Valerianella locusta. LWT Food Sci. Technol. 44, 2285-2289.

Grzegorzewski, F., Rohn, S., Kroh, L.W., Geyer, M., Schlüter, O., 2010. Surface morphology and chemical composition of lamb's lettuce (Valerianella locusta) after exposure to a low-pressure oxygen plasma. Food Chem. 122, 1145-1152.

Heredia, J.B., Cisneros-Zevallos, L., 2009. The effect of exogenous ethylene and methyl jasmonate on PAL activity: phenolic profiles and antioxidant capacity of carrots (Daucus carota) under different wounding intensities. Postharvest Biol. Technol. 51, 242-249.

Kang, H.M., Saltveit, M.E., 2002. Antioxidant capacity of lettuce leaf tissue increases after wounding. J. Agric. Food Chem. 50, 7536-7541.

Keener, K.M., Jensen, J.L., Valdramidis, V.P., Byrne, E., Connoly, J., Mosnier, J.P., Cullen, P.J., 2012. Decontamination of Bacillus subtilis spores in a sealed package using a non-thermal plasma system. Plasma for Bio-Decontamination, Medicine and Food Security, NATO Science for Peace and Security Series A: Chemistry and Biology. Springer.

Lichtenthaler, H.K., Wellburn, A.R., 1983. Determination of total carotenoids and chlorophylls a and b of leaf in different solvents. Biochem. Soc. Trans. 11, 591-592.

Montie, T.C., Kelly-Wintenberg, K., Roth, J.R., 2000. An overview of research using the one atmosphere uniform glow discharge plasma (OAUGDP) for sterilization of surfaces and materials. IEEE Trans. Plasma Sci. 28, 41-50.

Moreau, M., Orange, N., Feuilloley, M.G.J., 2008. Non-thermal plasma technologies new tools for bio-decontamination. Biotechnol. Adv. 26, 610-617.

Muntada, V., Gerschenson, L.N., Alzamora, S.M., Castro, M.A., 1998. Solute infusion effects on texture of minimally processed kiwifruit. J. Food Sci. 63, 616-620.

Naczk, M., Shahidi, F., 2004. Extraction and analysis of phenolics in food. J. Chromatogr. A 1054, 95-111.

Noriega, E., Shama, G., Laca, A., Díaz, M., Kong, M.G., 2011. Cold atmospheric gas plasma disinfection of chicken meat and chicken skin contaminated with Listeria innocua. Food Microbiol. 28, 1293-1300.

Odriozola-Serrano, I., Hernàndez-Jover, T., Martìn-Belloso, O., 2007. Comparative evaluation of UV-HPLC methods and reducing agents to determine vitamin $C$ in fruits. Food Chem. 105, 1151-1158.

Pankaj, S.K., Misra, N.N., Cullen, P.J., 2013. Kinetics of tomato peroxidase inactivation by atmospheric pressure cold plasma based on dielectric barrier discharge. Innovative Food Sci. Emerg. Technol. 19, 153-157.
Pasquali, F., Olivi, P., Ragni, L., Berardinelli, A., Sirri, F., Meluzzi, A., 2010. Evaluation of the decontamination efficacy of gas plasma on table and hatching eggs. Proceedings of the XIIIth European Poultry Conference, Tours, France.

Prior, R.L., Wu, X., Schaich, K., 2005. Standardized methods for the determination of antioxidant capacity and phenolics in foods and dietary supplements. J. Agric. Food Chem. 53, 3101-3113.

Ragni, L., Berardinelli, A., Vannini, L., Montanari, C., Sirri, F., Guerzoni, M.E. Guarnieri, A., 2010. Non-thermal atmospheric gas plasma device for surface decontamination of shell eggs. J. Food Eng. 100, 125-132.

Re, R., Pellegrini, N., Proteggente, A., Pannala, A., Yang, M., Rice Evans, C., 1999. Antioxidant activity applying an improved ABTS radical cation discoloration assay. Free Rad. Biol. Med. 26, 1231-1237.

Reyes, L.F., Cisneros-Zevallos, L., 2003. Wounding stress increases the phenolic content and antioxidant capacity of purple-flesh potatoes (Solanum tuberosum L.). J. Agric. Food Chem. 51, 5296-5300.

Reyes, L.F., Villareal, E., Cisneros-Zevallos, L., 2007. The increase in antioxidant capacity after wounding depends on the type of fruit or vegetable tissue. Food Chem. 101, 1254-1262.

Rocculi, P., Romani, S., Dalla Rosa, M., 2005. Effect of MAP with argon and nitrous oxide on quality maintenance of minimally processed kiwifruit. Postharvest Biol. Technol. 35, 319-328.

Rolny, R., Costa, L., Carrión, C., Guiamet, J.J., 2011. Is the electrolyte leakage assay an unequivocal test of membrane deterioration during leaf senescence? Plant Physiol. Biochem. 49, 1220-1227.

Rush, E.C., Patel, M., Plank, L.D., Ferguson, L.R., 2002. Kiwifruit promotes laxation in the elderly. Asia Pac. J. Clin. Nutr. 11, 164-168.

Selcuk, M., Oksuz, L., Basaran, P., 2008. Decontamination of grains and legumes infected with Aspergillus spp: and Penicillium spp. by cold plasma treatment. Bioresour. Technol. 99, 5104-5109.

Singleton, V.L., Rossi, J.A., 1965. A colorimetry of total phenolics with phosphomolybdic-phosphotungstic acid reagents. Am. J. Enol. Vitic. 16, 144158

Surowsky, B., Fischer, A., Schlueter, O., Knorr, D., 2013. Cold plasma effects on enzyme activity in a model food system. Innovative Food Sci. Emerg. Technol.19, 146-152.

Tappi, S., Berardinelli, A., Ragni, L., Dalla Rosa, M., Guarnieri, A., Rocculi, P., 2014 Atmospheric gas plasma treatment of fresh-cut apples. Innovative Food Sci. Emerg. Technol. 21, 114-122.

Tavarini, S., Degl'Innocenti, E., Remorini, D., Massai, R., Guidi, L., 2008. Antioxidant capacity, ascorbic acid: total phenols and carotenoids changes during harvest and after storage of Hayward kiwifruit. Food Chem. 107, 282-288.

Tylewicz, U., Panarese, V., Laghi, L., Rocculi, P., Nowacka, M., Placucci, G., Dalla Rosa, M., 2011. NMR and DSC water study during osmotic dehydration of Actinidia deliciosa and Actinidia chinensis kiwifruit. Food Biophys. 6, 327-333.

Varoquaux, P., Lecendre, I., Varoquaux, F., Sounty, M., 1990. Change in firmness of kiwifruit after slicing. Sci. Aliments 10, 127-139.

Vinson, J.A., Su, X., Zubik, L., Bose, P., 2001. Phenol antioxidant quantity and quality in foods: fruits. J. Agric. Food Chem. 49, 5315-5321.

Wang, R.X., Nian, W.F., Wu, H.Y., Feng, H.Q., Zhang, K., Zhang, J., Zhu, W.D., Becker, K. H., Fang, J., 2012. Atmospheric-pressure cold plasma treatment of contaminated fresh fruit and vegetable slices: inactivation and physiochemical properties evaluation. Eur. Phys. J. D 66, 276. 